\title{
Acute Respiratory Distress Syndrome and Pneumothorax after Synthetic Cannabinoid Intoxication
}

\author{
Ali Aygün', Burak Katipoğlu², Melih İmamoğlu³, Mehmet Kılıç4, Bekir Sami Karapolatt ${ }^{5}$ Atila Türkyılmaz \\ 'Department of Emergency Medicine, Ordu University Traning and Research Hospital, Ordu, Turkey \\ ${ }^{2}$ Clinic of Emergency Medicine, Ankara Education and Research Hospital, Ankara, Turkey \\ ${ }^{3}$ Clinic of Emergency Medicine, Rize State Hospital, Rize, Turkey \\ ${ }^{4}$ Clinic of Thoracic Surgery, İstanbul Yedikule Chest Diseases and Thoracic Surgery Training and Research Hospital, İstanbul, Turkey \\ ${ }^{5}$ Department of Thoracic Surgery, Karadeniz Technical University School of Medicine, Trabzon, Turkey
}

\begin{abstract}
Synthetic cannabinoids, whose effects are derived from CB1 and CB2 receptors in the nervous system, have come to represent a significant public health problem with the rapid increase in their use in the young and adult population. Synthetic cannabinoids are known as Spice in Europe, K2 in America, and bonsai or Jamaica in Turkey. A 25-year-old male was brought to the emergency department after being found by relatives in an unconscious state. Respiratory arrest developed, and the patient was intubated. Preliminary diagnoses of bonsai intoxication and respiratory failure were made, and the patient was transferred to our university hospital intensive care unit. Acute respiratory stress syndrome developed during monitoring. Mechanical ventilatory support was administered in the intensive care unit. Respiratory difficulty and chest pain developed one day after extubation. Chest radiography revealed pneumothorax in the left lung, and a chest tube was inserted. The patient was discharged in a healthy condition on the $11^{\text {th }}$ day of hospitalization. Respiratory depression and acute pulmonary injury can develop in patients with bonsai intoxication.
\end{abstract}

Keywords: Bonsai, respiratory depression pneumothorax, synthetic cannabinoid

\section{Introduction}

Bonsai, which contains various different synthetic cannabinoids (SCs) is widely used by young people because it is cheaper and more easily available than narcotic drug,marijuana and cocaine (1). The most common side effects are sweating, tachycardia, tremor, nausea, vomiting, hyper/hypotension, agitation, confusion, and respiratory depression.

This report describes the case of a patient with respiratory depression and acute respiratory distress syndrome (ARDS) developing following bonsai use and subsequent pneumothorax. It also discusses the side effects of bonsai use in the respiratory system and provides information from the literature.

\section{Case Presentation}

A 25-year-old male was found unconscious at home by relatives and was brought to a nearby emergency department. At his initial examination, his general condition was poor and he was unconscious. Respiratory arrest developed, and he was intubated. SC intoxication and respiratory failure were diagnosed in light of the history of bonsai use. On the second day, he was referred to our university hospital intensive care unit from the state hospital. Mechanical ventilatory support was administered. Widespread bilateral infiltration was observed on the posteroanterior chest radiography on the second day of hospitalization. On the second day, his blood gas $\mathrm{pH}$ was 7.18, arterial partial pressure of oxygen $\left(\mathrm{PaO}_{2}\right)$ was $140 \mathrm{mmHg}$, arterial partial pressure of carbon dioxide $\left(\mathrm{PaCO}_{2}\right)$ was $65 \mathrm{mmHg}$, bicarbonate $\left(\mathrm{HCO}_{3}\right)$ was $18 \mathrm{mmol} /$ Land oxygenation index $\left(\mathrm{PaO}_{2} / \mathrm{FiO}_{2}\right)$ was $140 \mathrm{mmHg}$; in the light of the sudden onset, bonsai intoxication-related ARDS was suspected. The mechanical ventilator employed due to ARDS was adjusted to a tidal volume of 5-7 $\mathrm{mg} / \mathrm{kg}$, high positive end-expiratory pressure (PEEP) and daily blood gas values. On the eight day of hospitalization, his GCS score was 14, blood gas $\mathrm{pH}$ was 7.39, $\mathrm{PaO}_{2}$ was 260 $\mathrm{mmHg}, \mathrm{PaCO}_{2}$ was $43 \mathrm{mmHg}, \mathrm{HCO}_{3}$ was $26 \mathrm{mmol} / \mathrm{Land} \mathrm{PaO}_{2} / \mathrm{FiO}_{2}$ was $577 \mathrm{mmHg}$. A sufficient tidal volume was achieved at low pressures. The patient met the weaning criteria and was extubated. Sudden-onset respiratory difficulty and chest pain developed the following day. Posteroanterior chest radiography was performed. Pneumothorax was detected in the left lung, and tube thoracostomy was performed (Fig- 


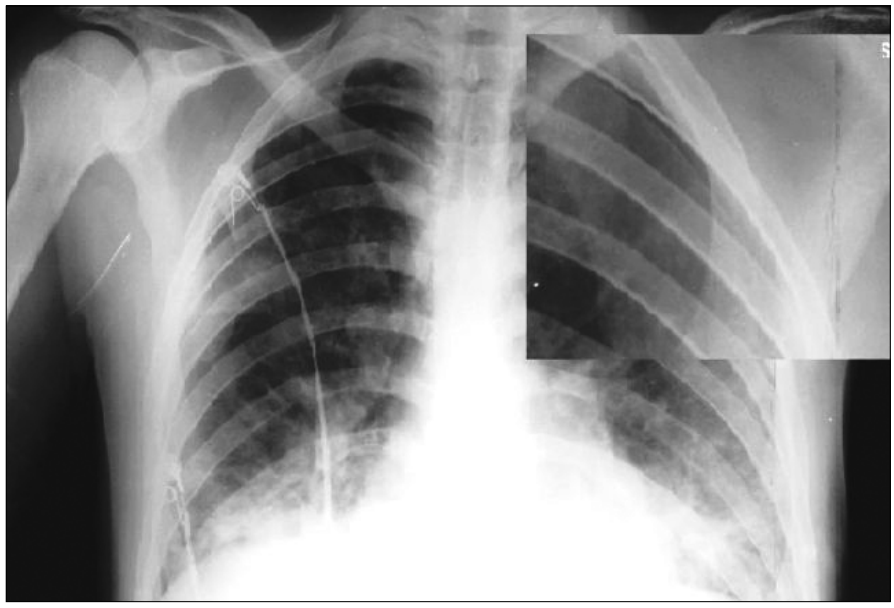

Figure 1.Visceral pleural margin (small image) of pneumothorax developing in the left lung on performing posteroanterior chest radiography

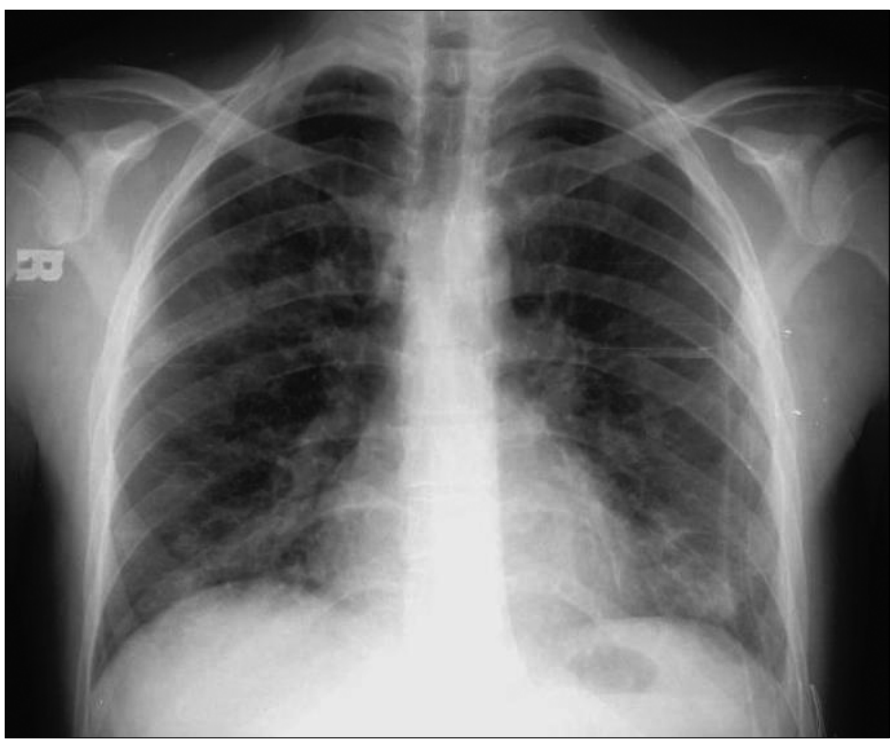

Figure 2. Control posteroanterior chest radiograph after the drain was removed

ure 1). The drain tube was removed in the absence of air leakage from the drain; pneumothorax was not seen on performing control radiography (Figure 2). His GCS score was 15 , and his general condition was good and vital findings were stable. There was no respiratory difficulty, and he was discharged in a healthy condition on the $11^{\text {th }}$ day of hospitalization.

\section{Discussion}

SCs were initially used in Europe and then gradually spread worldwide (2). The American Association of Poison Control Centers reported 53 cases of exposure to bonsai in 2009 and 13,000 cases in 2011 (3). This increase is responsible for tremendous increase in bonsai use in Turkey, despite the absence of official figures to date. We attribute this increase to the low cost of bonsai and its easy availability that is associated with the absence of supervision among the young, urban population.

Similar to marijuana, the chronic use of SCs leads to dependence syndrome, withdrawal symptoms, and psychiatric symptoms (1). However, in contrast to marijuana, acute intoxication findings more closely resemble those seen during sympathomimetic drug use. Despite fre- quent side effects involving the cardiopulmonary system, such as hyper/hypotension, confusion, and respiratory depression, clinical symptoms and presentations can vary. In the management of SC toxicity, supportive treatment, such as fluid and electrolyte replacement, benzodiazepines for agitation and anxiety, and non-invasive or invasive ventilatory support for respiratory failure, has been suggested $(4,5)$.

In a study in Turkey, Köklü et al. (6) reported myocardial infarction following bonsai use. In our case, respiratory arrest following bonsai use and pneumothorax developed after ARDS. We attribute this to SCs causing toxic injury to the pulmonary parenchymal tissue. SCs causing vasoconstriction and endothelial dysfunction and resulting in injury by creating nutrition problems in the peripheral pulmonary parenchyma may account for the pathophysiology of the respiratory side effects in our patient. Kaya et al. (5) reported a decrease in clinical findings at the 3-h observation after bonsai use. However, this may vary depending on the variety of SCs in the bonsai used and the intake amount. The pulmonary complications developing in our patient persisted until the $10^{\text {th }}$ day after substance use. Therefore, we think that it is important for physicians who monitor such patients to keep the monitoring or hospitalization period relatively lengthy to be able to recognize such potential complications.

\section{Conclusion}

Severe respiratory depression and ARDS can develop in association with bonsai use. The development of pneumothorax can be a complication of respiration with mechanical ventilation in ARDS patients. The close monitoring of respiratory functions during the monitoring of such patients and the careful evaluation of pulmonary X-rays will permit the early diagnosis and treatment of pulmonary complications.

Informed Consent: Written informed consent was obtained from patient who participated in this case.

Peer-review: Externally peer-reviewed

Conflict of Interest: No conflict of interest was declared by the authors.

Financial Disclosure: The authors declared that this study has received no financial support

\section{References}

1. Vardakou I, Pistos C, Spiliopoulou Ch. Spice drugs as a new trend: Mode of action, identification and legislation. Toxicol Lett 2010; 197: 157-62. [CrossRef]

2. Uchiyama N, Kikura-Hanajiri R, Ogata J, Goda Y. Chemical analysis of synthetic cannabinoids as designer drugs in herbal products. Forensic Sci Int 2010; 198: 31-8. [CrossRef]

3. AAPCC Issues Statement on the Synthetic Drug Abuse Prevention Act American Association of Poison Control Centre, 2012. Available from: http://www.aapcc.org/press/2/. [Accessed February 21, 2013]

4. Rosenbaum CD, Carreiro SP, Babu KM. Here today, gone tomorrow and back again? A review of herbal marijuana alternatives (K2, Spice), synthetic cathinones bath salts), Kratom, Salvia divinorum, methoxetamine and piperazines. J Med Toxicol 2012; 8: 15-32. [CrossRef]

5. Kaya S, Kaya FB, Zeytin AT, Tokkan I. Bonsai (JWH-018): An Unknown Cause Behind Change in State of Conscience. Causa Pedia 2014; 3: 960.

6. Köklü E, Yüksel iÖ, Bayar N, Üreyen ÇM, Arslan Ş. A new cause of silent myocardial infarction: Bonsai. Anadolu Kardiyol Derg 2015; 15: 69-70. [CrossRef] 